Arteterapia. Papeles de arteterapia y educación para inclusión social ISSN-e 1988-8309

http://dx.doi.org/10.5209/ARTE.57584

\title{
ALETHEIA, contra el olvido. Arte, trauma y memoria emocional. El proceso creador como elaboración del dolor
}

Del 26 al 30 de junio de 2017. Dentro de los cursos de Verano, El Escorial. Universidad Complutense de Madrid.

\section{Marián López Fernández-Cao ${ }^{1}$}

Decía la escritora Isak Dinesen: “todas las penas pueden soportarse si las insertas en una historia o cuentas una historia sobre ellas".

El curso "Aletheia, contra el olvido", dentro del proyecto I+D con el mismo nombre, exploró durante una semana las posibilidades psíquicas del proceso creador para elaborar el trauma y poder darle significado. El curso abordó la aplicación de las artes como forma de dar sentido a la memoria traumática y también el trabajo efectivo con las personas que sufren estrés postraumático, reflexionando sobre los procesos creadores desde el arte y la psicología pero también abordando el desarrollo de herramientas metodológicas destinadas a ser implantadas en situaciones de violencia con consecuencias traumáticas.

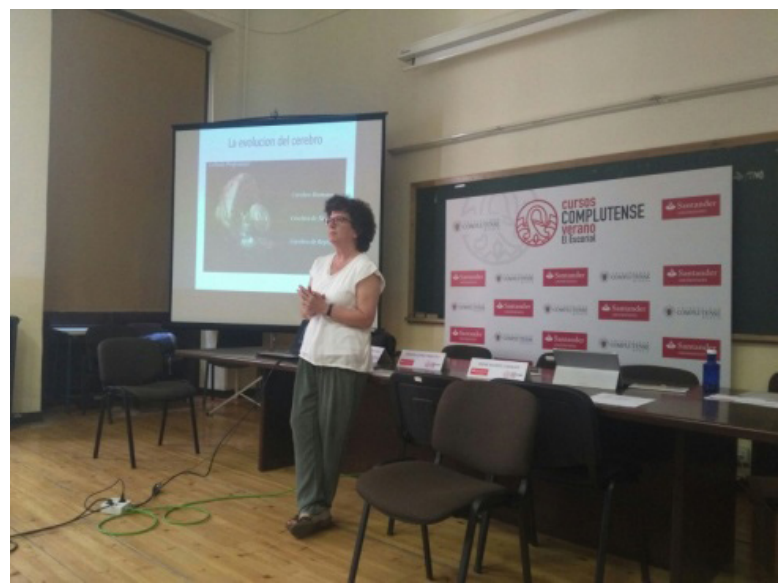

Imagen 1: Beatriz Rodriguez Vega explicando conceptos básicos sobre el trauma. 
Tras una introducción sobre las posibilidades del arte, realizada por Marián López Fdz. Cao, contamos con la presencia de Beatriz Rodríguez Vega, psiquiatra Jefa de sección Hospital Universitario La Paz, que abordó las terapias narrativas como ayuda para la superación del trauma.

Por otro lado, además de la Dra. Rodríguez Vega, intervinieron psicoanalistas como Jorge Marugán y Nora Levinton Dolman, que reflexionaron desde el punto de vista del psiquismo, en la creación como vía de elaboración del trauma. También Irene Solbes y Carmen López Escribano reflexionaron desde la psicología, el potencial de las artes en el trauma.

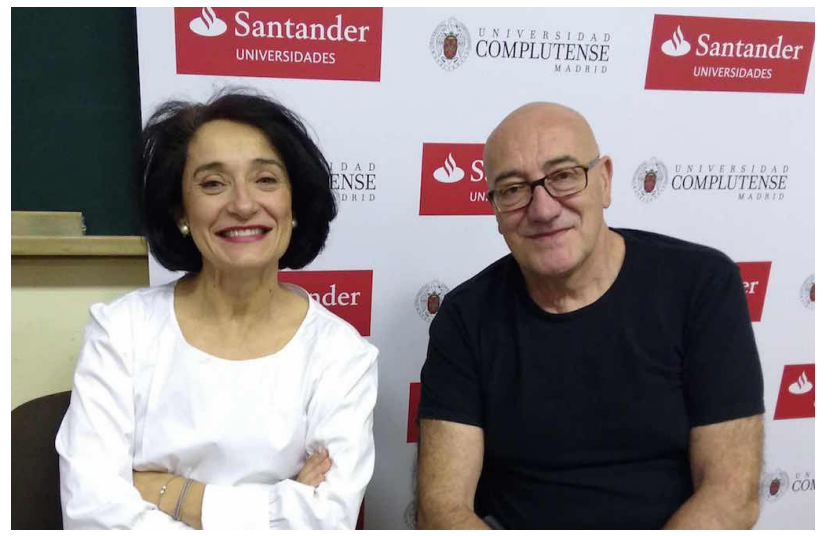

Imagen 2: La directora del curso, Marián López Fernández Cao, junto a Antonio Altarriba

La intervención de artistas como Rogelio López Cuenca, que se centró en los procesos creadores en torno al trauma colectivo y su obra "Málaga 1937"; las artistas componentes de Art al Quadrat, que reflexionaron sobre el proceso creador de su obra "Las jotas republicanas"; y Antonio Altarriba, guionista de novela gráfica que reflexionó sobre su obra "El arte de volar" y el cómic como instrumento para elaborar la memoria emocional, sirvieron para entrar en la complejidad del proceso creador en la exteriorización, elaboración y construcción colectiva de un pasado que pueda integrarse en el presente sin causar dolor.

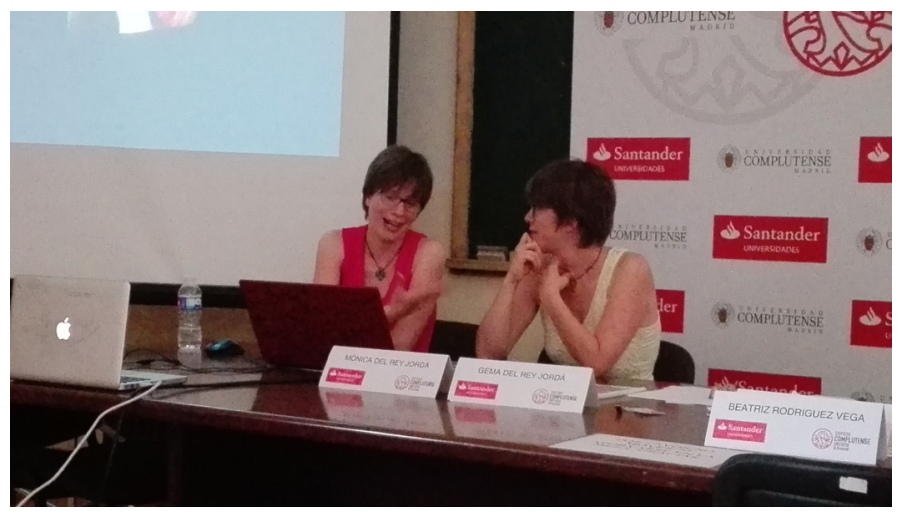

Imagen 3: Las artistas de "Art al Quadrat" 
Y desde el punto de vista de Arteterapia, Chris Nicholson, investigador del Centro de Estudios Psicoanalíticos de la Universidad de Essex, reflexionó sobre niños y adolescentes ante el trauma y sus aproximaciones creativas. Del mismo modo, Mónica Cury y Ana Hernando, arteterapeutas, relataron parte de su experiencia en el abordaje del trauma desde el arteterapia.

Además, uno de los días pudimos disfrutar de la mano de Alberto Gamoneda, educador del museo Thyssen, de un itinerario por el museo centrado en la idea del trauma y la conexión con vivencias personales a través de la visualización de las obras.

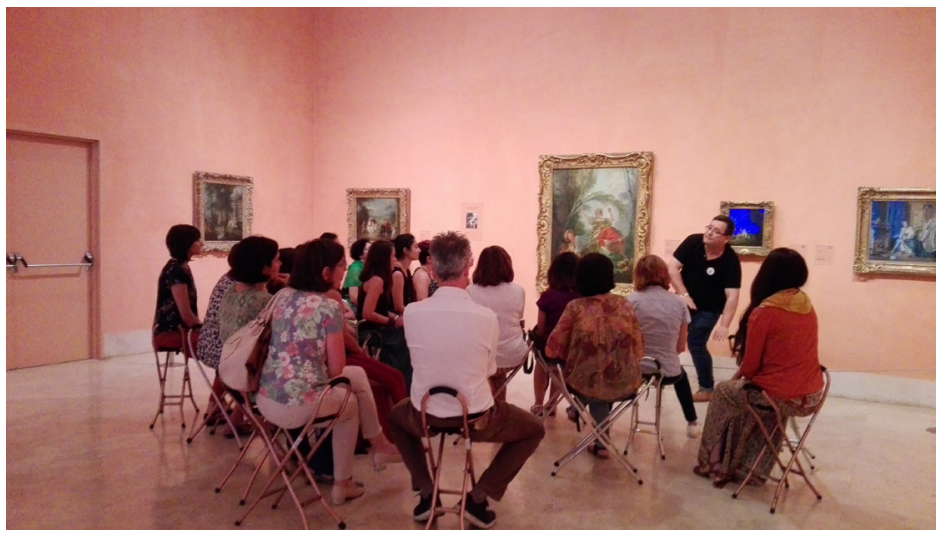

Imagen 4. Visita al Museo Thyssen-Bornemisza

Finalmente, el artista Gustavo Germano cerró con la presentación de su obra "Ausencias" la reflexión sobre cómo los procesos creadores colectivos pueden ayudar a elaborar los procesos traumáticos.

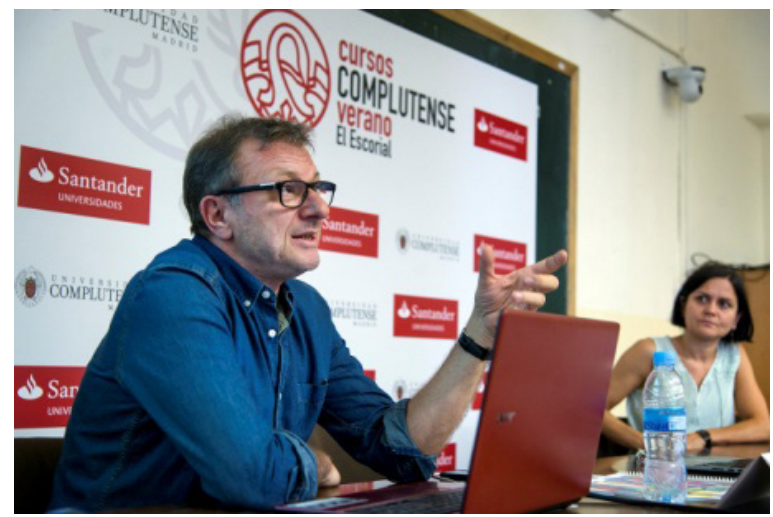

Pie de página. Imagen 5: Gustavo Germano durante la conferencia de clausura del curso, junto a Irene Solbes, secretaria del curso 